\title{
Language Development as An Objective Indicator of Neurodevelopment
}

\author{
Alejandra Auza B* \\ Language and Cognition Laboratory, Hospital General, Mexico
}

*Corresponding author: Alejandra Auza B, Language and Cognition Laboratory, Hospital General, Mexico

\section{Short Communication}

Language development is an objective indicator of developmental and cognitive skills in children. It is also one of the fundamental pillars for a child to acquire autonomy and be able to adapt to social and academic situations. A language delay (including both verbal and non-verbal skills) is an indicator that some aspect of development in young children is not going well. Language delays may be primarily due to four causes: hearing problems, neurodevelopmental conditions, such as the risk of having Developmental Language Disorder (DLD, formerly Specific Language Impairment -SLI-), Intellectual Disability -which at an early age is labeled as Developmental Global Disorder (DGD), or Autism Spectrum Disorder (ASD).

\section{Hearing Problems}

According to WHO (2000), 10\% of children are born deaf or hard-to-hearing. To a large extent, neonatal hearing screening can detect most of individuals with hearing loss, when there is a genetic or congenital etiology. Birth defects also include hearing loss and congenital deafness; it is estimated that between 2,000 and 6,000 children are born with these conditions each year in Mexico [1]. However, for those individuals with mild or moderate hearing loss, which is not detected by neonatal screening, a delay in language development can be evidenced around eighteen months of age. For example, recurrent otitis media has been known to contribute to language delays in young children under 2 years of age. However, a systematic review informed that it only contributes to phonological deficits in children [2]. Recurrent otitis interferes with the quality of the sound signal received by the child, especially the perception of some phonemes (e.g. fricative and voiceless sounds) but is not directly related to language and communication delays.

\section{Late Talkers (LT)}

When hearing loss is excluded as the cause of language delays, the developmental condition to be considered as the most prevalent is "Late Talker" (LT). According to various authors [3$5]$, this condition exhibits a prevalence of $13.5 \%$, which is not caused by sensory, anatomical or neurological problems. The delay is primary manifested, but not exclusively, in the domain of expressive language (production of gestures, words and sentences) $[6,7]$. About $70-75 \%$ of LTs will catch up to their peers at 36 months of age. But approximately $25-30 \%$ of these children will continue with more severe language difficulties, which may evolve into a Developmental Language Disorder (DLD) [8]. Most of the studies about LTs agree that these children produce less than 50 words $[9,10]$ and have not combined words at 24 months $[11,12]$. In many cases, children under the age of three, who speak little or not at all, go unnoticed at school or clinical services, since initial language delays are generally not considered a major problem that should be addressed by the health and/or education system.

\section{Intellectual Disability (ID)}

Neonatal metabolic screening is mandatory in many countries, and since 1998, it has been performed in all newborns in Mexico. This screening can detect congenital or metabolic conditions that can be treated promptly to prevent irreversible conditions such as ID. According to WHO [13], the frequency of congenital anomalies in the world is 2 to $3 \%$ in live births. However, there is still a big proportion of children with a risk of ID that go undetected in developing countries. In a recent study, Rizzoli Córdoba [14] reported that $4.2 \%$ of children were at risk of delay, being the communication and cognition domains the most affected at 24 months of age. Although the diagnosis of ID cannot be established until the psychometric measurement of IQ around the age of 4 , the data suggests that in developing countries, Global Developmental Delay [15] with communication, cognition and other developmental domains affected might be more pervasive due to socio-demographic associated factors, such as the insufficient consumption of nutrients during pregnancy, poorer access to healthcare and screening, among others. According to WHO [13], it is estimated that about $94 \%$ of severe congenital anomalies occur in low- and middle-income countries. Moreover, in these countries $39 \%$ of children younger than 5 years, might be at risk of not reaching their developmental potential [16]. 


\section{Autism Spectrum Disorder (ASD)}

In the third order of prevalence, language delays in young children may be associated with the risk of presenting ASD, which is characterized by difficulties in the use of social communication (among other features), although said difficulties are not exclusively pragmatic [17]. This condition is frequent in neurodevelopmental disorders being present in about $1 \%$ of the children [18]. At least half of the children with ASD who develop language, lag behind their peers in phonological processing, use of gestures, symbolic play and social routines, expressive and receptive vocabulary, grammar (morphology and syntax), and pragmatics (social use of language). Early delays include social difficulties to establish joint attention with adults and peers, lack of response to their names, problems initiating social play and a reduced production of gestures and symbolic play. Said delays, specifically those with difficulties to establish joint attention and the lack of response to their own names, commonly mislead parents into falsely suspecting their child might have hearing problems. Moreover, delays on social and communicative outcomes, are sometimes unseen by health and education professionals.

\section{What is recommended?}

Although neonatal metabolic and hearing screenings are good sources for early detection of some conditions that affect child development, one of the greatest challenges for developing countries is to establish screening models that are useful for early detection of language delays before 30 months of age. No recommendations exist for screening language delays at these ages, being early identification a big challenge. An implication of this review is twofold: First, typical developmental language benchmarks of children under 30 months of age should be well known among primary health care clinicians, pediatricians, otolaryngologists, neurologists and preschool educators in order to early identify language delays. Second, identification of language delays under three years of age can serve as an important step forward for public health, because language can just be a symptom of a developmental condition. Finally, there is sufficient evidence supporting the effectiveness of treating language delays and disorders in children [19]. The development of expressive language, mainly the onset of first gestures, words and phrases is a relevant clinical tool, since its early appearance is associated to better long-term life outcomes and to better prognosis [20]. Early identification can help them receive a diagnosis and reduce the negative impact of any of these conditions throughout life.

\section{References}

1. National Academy of Medicine (2014) Neonatal hearing screening and early intervention. Position Statement. P Berruecos (Coord.). Mexico

2. Paul R (1991) Profiles of toddlers with slow expressive language development. Topics in Language Disorders 11: 1-13.

3. Horwitz SM, Irwin JR, Briggs Gowan MJ, Bosson HJM, Mendoza J, et al. (2003) Language delay in a community cohort of young children. Journal American Academy of Child and Adolescent Psychiatry 42: 932-940.
4. Rescorla L, Mirak J, Singh L (2000) Vocabulary growth in late talkers: lexical development from 2;0 to 3;0. Journal of Child Language 27: 293311.

5. Zubrick SR, Taylor CL, Rice M (2007) Late Language Emergence at 24 Months: An Epidemiological Study of Prevalence, Predictors, and Covariates. Journal of Speech Language and Hearing Research 50(6): 1562-1592.

6. Thal D, Tobias S (1994) Relationships between language and gesture in normally developing and late-talking toddlers. Journal of Speech and Hearing Research 37: 157-170.

7. Tsybina I, Eriks Brophy A (2007) Issues in Research on Children with Early Language Delay. Contemporary Issues in Communication Science and Disorders 34: 118-133.

8. Leonard LB (2014) Children with Specific Language Impairment. MIT Press, Cambridge, Massachusetts, USA.

9. Rescorla L (2011) Late talkers: do good predictors of outcome exist? Developmental Disabilities Research Reviews 17(2): 141-150.

10. Rescorla L, Schwartz E (1990) Outcome of toddlers with specific expressive language delay. Applied Psycholinguistics 11: 393-407.

11. Reilly S, Tomblin B, Law J, McKean C, Mensah FK, et al. (2014) Specific language impairment: a convenient label for whom? International Journal of Language and Communication Disorders 9(4): 416-451.

12. Rescorla L, Hadick Wiley M, Escarce E (1993) Epidemiological investigation of expressive language delay at age two. First Language 13: 5-22.

13. https://www.who.int/news-room/fact-sheets/detail/congenitalanomalies

14. Rizzoli Córdoba A, Ortega Ríosvelasco F, Villasís Keever MA, Pizarro Castellanos M, Buenrostro-Márquez G, et al. (2014) Reliability for detection of developmental problems using the semaphore from the Child Development Evaluation test: Is a yellow result different from a red result. Boletín Médico del Hospital Infantil de México 71: 277-285.

15. Turygin N, Matson JL, Williams LW, Belva BC (2014) The relationship of parental first concerns and autism spectrum disorder in an early intervention sample. Research in Autism Spectrum Disorders 8(2): 5360.

16. Black MM, Walker SP, Fernald LCH, Andersen CT, DiGirolamo AM, et al. (2017) Advancing Early Childhood Development: from Science to Scale 1. Early childhood development coming of age: science through the life course. Lancet 389: 77-90.

17. Tager Flusberg H (2010) The Origins of Social Impairments in Autism Spectrum Disorder: Studies of Infants at Risk. Neural Network 23(8-9): 1072-1076.

18. Fombonne E, Marcin C, Manero AC, Bruno R, Diaz C, et al. (2016) Prevalence of autism spectrum disorders in Guanajuato, Mexico: The Leon survey. Journal of Autism and Developmental Disorders 46(5): 1669-1685.

19. Wallace IF, Berkman ND, Watson LR, Coyne Beasley T, Wood CT, et al (2015) Screening for Speech and Language Delay in Children 5 Years Old and Younger: A Systematic Review Pediatrics 144(4).

20. Kover ST, Edmunds SR, Weismer SE (2016) Brief report: Ages of language milestones as predictors of developmental trajectories in young children with autism spectrum disorder. Journal of Autism and Developmental Disorders 46(7): 2501-2507. 


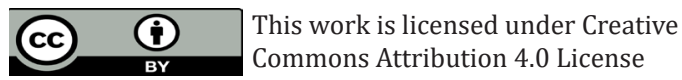

To Submit Your Article Click Here: Submit Article

DOI: $10.32474 /$ SJO.2019.03.000158

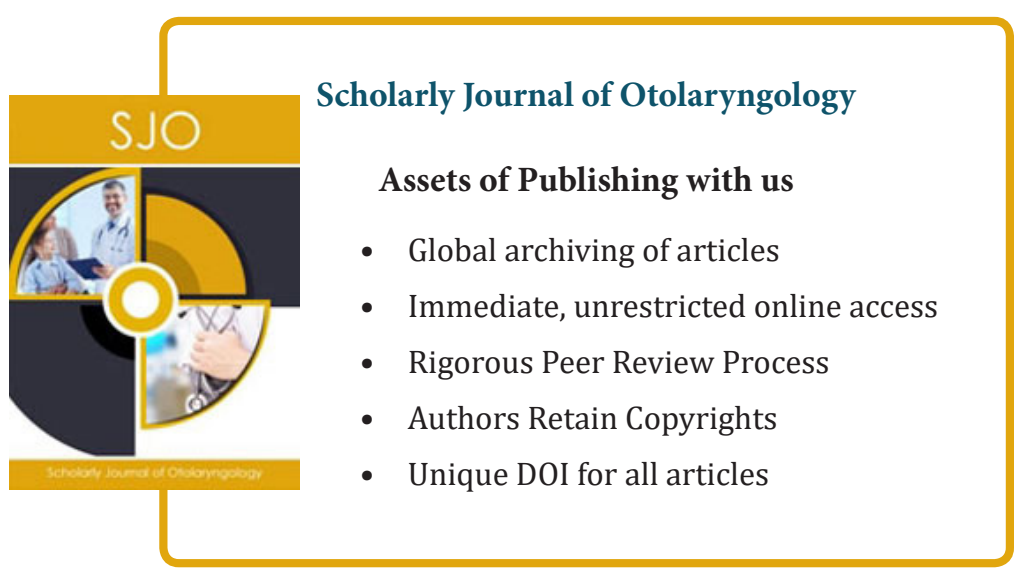

